\title{
First report of the presence of Verticillium dahliae VCG1A in Australia
}

\author{
Toni A. Chapman ${ }^{1}$ - Grant A. Chambers ${ }^{1}$. \\ Karen Kirkby $^{2}$ - Rafael M. Jiménez-Díaz ${ }^{3,4}$
}

Received: 7 September 2015 / Accepted: 4 April 2016 / Published online: 12 April 2016

(C) Australasian Plant Pathology Society Inc. 2016

\begin{abstract}
For 32 years, cotton grown in NSW has been monitored for Verticillium wilt, with isolates of Verticillium dahliae Kleb. stored in the NSW Department of Primary Industries culture collection. An increase in disease severity in the 2013/14 season suggests a more virulent pathogenic strain may have been introduced. Eight $V$. dahliae isolates were selected for vegetative compatibility group (VCG) analysis using molecular assays and nit mutant testing. Two of the eight isolates were identified as the highly virulent defoliating VCG1A, making this the first record of VCG1A in Australia.
\end{abstract}

Keywords Verticillium wilt · Cotton · Defoliating ·

Non-defoliating

Verticillium dahliae Kleb. is a strictly asexually-reproducing, soil borne fungus in the phylum Ascomycota, that causes vascular disease in about 400 plant species and is responsible for major economic loss in a diverse range of crop production

Toni A. Chapman

toni.chapman@dpi.nsw.gov.au

1 Elizabeth Macarthur Agricultural Institute, NSW Department of Primary Industries, Woodbridge Road, Menangle, NSW 2568, Australia

2 Australian Cotton Research Institute, Locked Bag 1000, Narrabri, NSW 2390, Australia

3 Departamento de Agronomía, College of Agriculture and Forestry (ETSIAM), Universidad de Córdoba, Campus de Excelencia Internacional Agroalimentario ceiA3, Avenida Menéndez Pidal s/n, 14004 Córdoba, Spain

4 Instituto de Agricultura Sostenible (IAS), Consejo Superior de Investigaciones Científicas (CSIC), Campus de Excelencia Internacional Agroalimentario ceiA3, Avenida Menéndez Pidal s/n, 14004 Córdoba, Spain systems worldwide (EFSA 2014; Inderbitzin et al. 2011; Pegg and Brady 2002). The problems caused by $V$. dahliae are exacerbated by its extensive and expanding host range (Subbarao et al. 1997) and its ability to survive in soil by means of microsclerotia, in the absence of a host, for up to 14 years (Wilhelm 1955). Cotton is an economically important crop, with exports from Australia worth more than \$2 billion annually. The ongoing revenue from this product is integral to Australian agribusiness. Verticillium wilt is a major problem in cotton worldwide and was first observed in Australia in 1967 (Evans and Paull 1967). Crop and disease monitoring has occurred since 1983 on a seasonal basis, with plants exhibiting symptoms of Verticillium wilt collected for isolation of $V$. dahliae.

Strains of $V$. dahliae infecting cotton are classified into two pathotypes: defoliating (D) and non-defoliating (ND). These strains are further categorised according to vegetative compatibility groups (VCGs) which are linked to host adaptation and often correlate with virulence on specific crops. In Australia, commercial cotton crops have been monitored and surveyed for the distribution, incidence and severity of Verticillium wilt caused by $V$. dahliae since 1983 (Kirkby et al. 2013). Verticillium wilt was described as the first major disease recorded in cotton following surveys in the 1984/85 season (Kirkby et al. 2013). The mean percentage incidence of Verticillium wilt in NSW varies between seasons but remains generally low; with the state average surpassing $10 \%$ only on four occasions. Prior to the 2013/2014 period, it was believed there was only a single VCG type present in Australian cotton; however, this changed in 2014 with the detection of the ND VCG2A strain (Smith et al. 2014). Since then, there have been ongoing concerns expressed by some growers and consultants of an increase in the severity of disease symptoms associated with Verticillium wilt along with an observed increase in the state average incidence from $5.5 \%$ in $2013 / 2014$ to $7.1 \%$ in 
$2014 / 2015$. The decision was made to further investigate the etiological agent using molecular tools to clarify the possible VCG present. A total of eight $V$. dahliae isolates, including representative historical isolates from the NSW DPI culture collection were examined.

Culture collection isolates of $V$. dahliae were originally obtained from affected cotton grown in commercial farms in NSW between 1983 and 2015. Pure cultures were grown on potato dextrose agar (PDA), single-spored, then stored in vials with distilled water at $12{ }^{\circ} \mathrm{C}$. Mycelia $(100 \mathrm{mg})$ from active cultures on PDA were used for DNA extraction as per manufacturer's instructions (Extract-N-Amp Plant PCR Kit, SigmaAldrich). Three molecular approaches were used for VCG and pathotype testing. Initially, eight isolates were tested using the method described in Berbegal et al. (2011), which provides a presumptive VCG type through the use of polymorphic markers. The primer pairs VdSSR1F/VdSSR1R, VdSNP1F/ VdSNP1R, VdSNP2F/VdSNP2R, and VdSNP3F/VdSNP3R were used as described and sequenced in both directions to determine the multilocus genotypes for each isolate. This result prompted the use of primers DB19/DB22 (Carder et al. 1994) to amplify a PCR marker specific to $V$. dahliae. The size of the amplified product distinguished between D and ND strains; 539 and 523 bp respectively. The third method was to amplify the Intergenic spacer (IGS) region using the primers VdIGSF1 and VdIGSR1 (Qin et al. 2006). Comparison of the amplicon sequence to known $V$. dahliae VCG typed reference isolates determined the presumptive VCG of each isolate. Molecular analysis of the samples using the primer pairs derived from microsatellite sequencing (Berbegal et al. 2011) revealed two isolates (DAR82592 and DAR82598, Table 1) to be VCG1A, the cotton D pathotype, thought to be exotic to Australia. The two Australian VCG1A isolates, when compared with the reference isolates (Papaioannou et al. 2013), aligned in the subregion P. This result prompted analysis using the Carder et al. (1994) and Qin et al. (2006) methods with both identifying the presumptive VCG1A isolates as D pathotype, thus supporting the initial VCG1A result. The eight isolates were sent to R.M. Jiménez-Díaz at the Instituto de Agricultura Sostenible (IAS), Consejo Superior de Investigaciones Científicas (CSIC), Córdoba, Spain for blind VCG testing using nitratenonutilizing (nit) mutants.

Single-spore cultures of each isolate were grown on PDA plates at $25 \pm 1{ }^{\circ} \mathrm{C}$ in the dark for 7 days for complementation tests of nit mutants. Nit mutants were generated on water agar-chlorate (WAC) (Korolev and Katan 1997) according to the methods of Collado-Romero et al. (2006) and Jiménez-Díaz et al. (2006), and phenotyped according to the methods of Correll et al. (1987). Complementation tests were performed as described in Collado-Romero et al. (2006) and JiménezDíaz et al. (2006). Phenotypically distinct nit mutants of an isolate were paired with complementing nit mutants of the Ohio Agricultural Research and Development Center (OARDC, The Ohio State University, Wooster, OH), reference strains of $V$. dahliae VCGs (VCG1, strain T9M [Code used by the OARDC to label the NitM mutant]; VCG3, strain 70-21; and VCG4A, strain $131 \mathrm{M}$ ) and Israeli nit testers (VCG2A, strain Cot200; VCG2B, strain Ep8M, and VCG4B, strain Pt15M) (Korolev et al. 2000) in all possible combinations.

Israeli nit testers of VCG2A, VCG2B, and VCG4B were previously shown to correlate with the

Table 1 VCG typing of eight historical collection isolates of Verticillium dahliae using the three described molecular assays and nit mutant testing for final VCG confirmation

\begin{tabular}{|c|c|c|c|c|c|c|c|c|c|c|}
\hline $\begin{array}{l}\text { Australian Culture } \\
\text { Collection Accession } \\
\text { Numbers }\end{array}$ & Year Isolated & $\mathrm{SSR}^{\mathrm{a}}$ & $\mathrm{SNP} 1^{\mathrm{a}}$ & $\mathrm{SNP}^{\mathrm{a}}$ & $\mathrm{SNP}^{\mathrm{a}}$ & $\begin{array}{l}\text { DB19/ } \\
\text { DB22 }\end{array}$ & IGS Sequence $^{\mathrm{c}}$ & $\begin{array}{l}\text { GenBank } \\
\text { Accession } \\
\text { Numbers }\end{array}$ & $\begin{array}{l}\text { Presumptive } \\
\text { Molecular } \\
\mathrm{VCG}^{\mathrm{d}}\end{array}$ & $\begin{array}{l}\text { Nit Mutant } \\
\text { Result }\end{array}$ \\
\hline DAR82591 & $2009 / 2010$ & 3 & 4 & 1 & 1 & ND & $2 \mathrm{~A}$ & KU743353 & $2 \mathrm{~A}$ & $2 \mathrm{~A}$ \\
\hline DAR82592 & 2010/2011 & 4 & 2 & 2 & 2 & $\mathrm{D}$ & $1 \mathrm{~A}$ & KU743354 & $1 \mathrm{~A}$ & $1 \mathrm{~A}$ \\
\hline DAR82593 & $2010 / 2011$ & 3 & 4 & 1 & 1 & ND & No Result & KU743355 & $2 \mathrm{~A}$ & $4 \mathrm{~B}$ \\
\hline DAR82594 & $2011 / 2012$ & 3 & 4 & 1 & 1 & ND & $2 \mathrm{~A}$ & KU743356 & $2 \mathrm{~A}$ & $2 \mathrm{~A}$ \\
\hline DAR82595 & $2011 / 2012$ & 3 & 4 & 1 & 1 & ND & $2 \mathrm{~A}$ & KU743357 & $2 \mathrm{~A}$ & $2 \mathrm{~A}$ \\
\hline DAR82597 & $2013 / 2014$ & 3 & 4 & 1 & 1 & ND & $2 \mathrm{~A}$ & KU743358 & $2 \mathrm{~A}$ & $2 \mathrm{~A}$ \\
\hline DAR82598 & $2013 / 2014$ & 4 & 2 & 2 & 2 & $\mathrm{D}$ & $1 \mathrm{~A}$ & KU743359 & $1 \mathrm{~A}$ & $1 \mathrm{~A}$ \\
\hline DAR82599 & $2013 / 2014$ & 1 & 3 & 4 & 1 & ND & 4B & KU743360 & $4 \mathrm{~B}$ & $4 \mathrm{~B}$ \\
\hline
\end{tabular}

${ }^{\text {a }}$ Primer names from Berbegal et al. 2011 to amplify the polymorphic markers for multilocus genotyping and result from the alignment, the collective result allowed for assignment of the presumptive molecular VCG (4)

${ }^{\mathrm{b}}$ Primer names from Carder et al. 1994 to amplify the product to distinguish between the ND and D pathotype

${ }^{\mathrm{c}}$ IGS sequence result using the protocol from Qin et al. 2006 and alignment with the isolates from Papaioannou et al. 2013

${ }^{\mathrm{d}}$ Confirmed presumptive VCG 

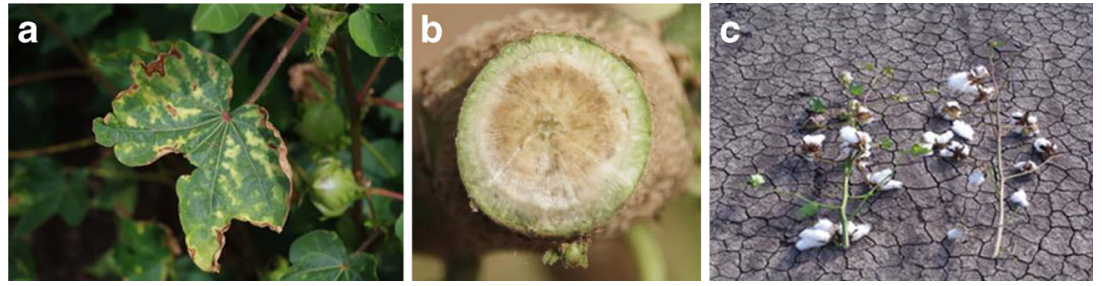

Fig. 1 a Cotton leaf mottle characteristic of Verticillium Wilt; b Vascular discolouration in a cotton stem infected with Verticillium dahliae; $\mathbf{c}$ Cotton plants attacked by non-defoliating (left) and defoliating VCG1A (right) strains of $V$. dahliae

international OARDC reference strains (Korolev et al. 2000; Korolev et al. 2008; Rowe 1995). The cotton defoliating strain T9 (the original defoliating pathotype from cotton in California) belongs to subgroup VCG1A (Bell 1994). Only isolates of this subgroup caused severe defoliation of cotton in previous studies (Daayf et al. 1995; Korolev et al. 2008). Thus, isolates strongly compatible with T9 (or strongly compatible with other testers) may be assigned to VCG1A (Korolev et al. 2008).

Plates for complementation tests were scored for prototrophic growth after 14 and 28 days of incubation. Complementation was indicated by the formation of a dense, aerial growth where mycelia from an unknown and a tester strain had met and formed a prototrophic heterokaryon. In such a case, the unknown mutant was considered vegetatively compatible with the tester strain and was assigned to the VCG of the tester strain. All tested isolates produced nit1 mutants, with DAR82594 forming NitM mutants. Complementing heterokaryons formed between nit mutants of the tested isolates and the international OARDC reference strains and Israeli tester strains. The morphology of heterokaryons in pairings of compatible nit mutants included prototrophic growth and formation of dense to scattered aerial mycelium and development of microsclerotia. Based on their positive complementation reactions with specific testers, the eight tested isolates were assigned to VCGs as shown in Table 1. Complementation tests were repeated once with the same results.

Single spore cultures of all eight $V$. dahliae have been deposited in the NSW DPI Herbarium culture collection with assigned accession numbers as indicated in Table 1. These results confirm that $V$. dahliae VCG1A is present in Australia and that one of the isolates collected and stored from the 2010/2011 season, was also VCG1A. This work confirmed that $V$. dahliae VCG1A defoliating pathotype is present in Australian cotton, with symptoms illustrated in Fig. 1.

Acknowledgments The authors wish to thank Dr Stephen Allen, Dr David Nehl (Department of Agriculture and Water Resources), and Dr Chris Anderson, Peter Lonergan, Bethany Cooper and Sharlene Roser (NSW DPI) for collecting plants samples and isolating and maintaining cultures. This research was made possible through funding from the Cotton Research and Development Corporation (CRDC).

\section{References}

Bell A (1994) Mechanisms of disease resistance in Gossypium species and variation in Verticillium dahliae. In: Proceedings of the World Cotton Research Conference I, 1994. CSIRO, pp 225-235

Berbegal M, Garzón C, Ortega A, Armengol J, Jiménez-Díaz RM, Jiménez -Gasco MM (2011) Development and application of new molecular markers for the analysis of genetic diversity in Verticillium dahliae populations. Plant Pathol 60:866-877

Carder JH, Morton A, Tabrett AM, Barbara DJ (1994) Detection and differentiation by PCR of subspecific groups within two Verticillium species causing vascular wilts in herbaceous hosts. Modern assays for plant pathogenic fungi: Identification, detection and quantification. CAB International, Wallingford, pp 91-97

Collado-Romero M, Mercado-Blanco J, Olivares-Garcia C, ValverdeCorredor A, Jiménez-Díaz RM (2006) Molecular variability within and among Verticillium dahliae vegetative compatibility groups determine by fluorescent amplified fragment length polymorphism and polymerase chain reaction markers. Phytopathology 96:485-495

Correll JC, Kittich CJR, Leslie JF (1987) Nitrate non-utilizing mutants of Fusarium oxysporum and their use in vegetative compatibility tests. Phytopathology 77:1640-1646

Daayf F, Nicole M, Geiger JP (1995) Differentiation of Verticillium dahliae populations on the basis of vegetative compatibility and pathogenicity on cotton. Eur J Plant Pathol 101:69-79

European Food Safety Authority (EFSA) (2014) Scientific opinion on the pest categorisation of Verticillium dahliae Kleb. Eur Food Saf Authority J 12:3928

Evans G, Paull RE (1967) Incidence and distribution of verticillium wilts in cotton crops of the Namoi Valley. Aust Inst Agric Sci Technol 33: 210-212

Inderbitzin P, Bostock RM, Davis RM, Usami T, Platt HW, Subbarao KV (2011) Phylogentics and taxonomy of the fungal vascular wilt pathogen Verticillium, with the descriptions of five new species. PLoS ONE 6, e28341

Jiménez-Díaz RM, Mercado-Blanco J, Olivares-García C, ColladoRomero M, Bejarano-Alcázar J, Rodríguez-Jurado D, GiménezJaime A, García-Jiménez J, Armengol J (2006) Genetic and virulence diversity in Verticillium dahliae populations infecting artichoke in eastern-central Spain. Phytopathology 96:288-298

Kirkby KA, Allen SJ, Lonergan PA (2013) Three decades of cotton disease surveys in NSW. Aust Crop Pasture Sci 64:774-779

Korolev N, Katan T (1997) Improved medium for selecting nitrate nonutilising (nit) mutants of Verticillium dahliae. Phytopathology 87:1067-1070

Korolev N, Katan J, Katan T (2000) Vegetative compatibility groups of Verticillium dahliae in Israel: their distribution and association with pathogenicity. Phytopathology 90:529-566

Korolev N, Korolev N, Pérez-Artés E, Mercado-Blanco J, BejaranoAlcázar J, Rodríguez-Jurado D, Jiménez-Díaz RM, Katan T, Katan J (2008) Vegatative compatibiilty of cotton-defoliating verticillium dahliae in Israel and its pathogenicity to various crop plants. Eur J Plant Pathol 122:603-617. doi:10.1007/10658-008-9330-1 
Papaioannou IA, Dimopoulou CD, Typas MA (2013) Structural and phylogenetic analysis of the rDNA intergenic spacer region of Verticillium dahliae. FEMS Microbiol Lett 347(1):23-32

Pegg GF, Brady BL (2002) Verticillium Wilts. CABI. doi:10.1079/ 9780851995298.0000

Qin QM, Vallad GE, Wu BM, Subbarao KV (2006) Phylogenetic analysis of phytopathogenic isolates of Verticillium spp. Phytopathology 96: 582-592

Rowe RC (1995) Recent progress in undertanding relationships between Verticillium species and subspecific groups. Phytoparasitica 23:31-38
Smith L, Scheikowski L, Bauer B, Lehane J, Allen S (2014) Pathogens in Australian Cotton. Cotton Research and Development Corporation on behalf of the 17th Australian Cotton Conference

Subbarao KV, Hubbard JC, Greathead AS, Spencer GA (1997) Verticillium Wilt. Compendium of lettuce diseases. The American Phytopahtological Society, St. Paul

Wilhelm S (1955) Longevity of Verticillium Wilt fungus in the laboratory and field. Phytopathology 45:180-181 